\title{
The Creation of the Teaching Situation In the Process of Making Multimedia Courseware
}

\author{
Yingqun Zhao \\ Department of Computer Science and Technology, Tonghua Normal University, Jilin \\ Tonghua, China, 134000 \\ 8924134@qq.com
}

Keywords: Multimedia courseware; teaching situation; situation creation

\begin{abstract}
Multimedia teaching courseware with large amount of information, illustrated, audio-visual integration, interactive and convenient advantages. Reasonable application in the classroom to reform the traditional teaching mode, improving teaching efficiency and teaching quality is of great significance. This paper mainly talks about the process of making multimedia courseware in teaching situation creation principle and method of analysis. In the teaching design, multimedia courseware and situational property fusion, making multimedia courseware teaching effect played more perfect.
\end{abstract}

The art of teaching is not only to impart knowledge, and more important is to awaken, motivation and inspiration. With the rapid development of multimedia technology, the application of multimedia courseware is more and more extensive. Large amounts of multimedia courseware walk into the classroom, because the multimedia courseware can make text, graphics, animation, video, audio and other multimedia perfect fusion, flexible form, and has a good interaction, to bring the students a new learning environment and cognitive style. In the teaching design how to create the situation creation to awaken students' experience, so as to promote the new knowledge learning, received good teaching effects, through the multimedia courseware make knowledge and situational appropriateness fusion, make multimedia courseware teaching effect played more perfect.

Use of multimedia courseware creation situation, can give students learn with life; bring vitality to the teachers' teaching. Creating situations have many kinds of methods, including reflection and action research is to improve the ability of teaching situation to create effective way. This article discuss about how to use multimedia courseware to create teaching situation, optimize the teaching process.

\section{The Principle of Situation Creation during Process of Making Courseware}

To create the situation of Courseware is carried out under the guidance of certain principles. Most can arouse the students' interest in learning of the teaching situation is a combination of the students familiar with the real life to create the teaching situation. Multimedia courseware situation create should focus on students' life experience, close to the students' "zone of proximal development" in order to receive good results. This article mainly discusses about objective principle, interest principle and the principle of authenticity.

The objective principle. The classroom life it is a basic way of creating teaching situation. Situation creation of Multimedia courseware in " emotional expression, create atmosphere" as the core design goals.

Teaching situation, must be carefully chosen and design, from the near to the distant, from the shallower to the deeper, from the outside to the inside, so that it can be suitable for students, close to the students' " zone of proximal development ", it can be easy for students to understand and accept. In such a learning environment to promote student will have the skills and knowledge to new knowledge migration. Enable students to solve the specific problems of method and experience enriches gradually, in the new situation to improve the students' ability to solve practical problems. 
The interest principle. Learning motivation is to interest, the interest is the student learning and study of direct power, therefore, situational interest is multimedia courseware creation to create one of the basic principles. Most can arouse the students' interest in learning is the teaching situation. It is a combination of the students familiar with the real life to create the teaching situation.

Multimedia courseware is a kind of new cognitive tool, it should not be rigid, monotonous, only with scientific and educational purposes, but should be novel, vivid, interesting, the full of beauty and charm, to meet students' curiosity to explore the unknown. The ideal multimedia courseware teaching situation should strive to achieve scientific, practical and interesting unity. But the requirement of each teaching situation at the same time to meet such properties may not be realistic. In the specific context design, should be a careful analysis of each situation, and accordingly determine the selection of focus; in the whole teaching process to make scientific, practical, interesting to achieve an appropriate balance. Multimedia courseware on the use of media should also be full of change; good at using the characteristics of different media to show different results, because of the change of information can cause the attention of learning object. The use of various forms of interest situated teaching, let students' autonomous learning, from experience to participate in joy, promoting students' active development, achieve good teaching effect.

The authenticity principle. Multimedia courseware creation can build simulation learning environment, the traditional teaching, not in the classroom teaching of limited time and space in the life of the present situation, with the aid of multimedia courseware design, the realistic simulation environment and virtual reality in the classroom teaching, so as to improve the efficiency of learning, achieve good teaching effect.

The real situation is usually the activities of daily living, authenticity has important potential energy resources, and it is often the problem based real life and reality show. Through the mining the rich teaching in students living, development and utilization of the surrounding community and the natural environment of the curriculum resources to create close to student life and cognitive basis of real situation. The student has the possibility to estimate they are learning content, how to apply the knowledge to solve practical problems, and the situation itself by helping students form of situational intention awareness, guide students activities.

\section{Courseware Situations Creates Method}

Good teaching situation can make the students actively and full of confidence, participate in the study. Make students' cognitive activity and emotional activities are organically combined, so as to promote the development of students' Non intelligence factors and healthy personality formation. Good teaching situation should make full use of teaching materials provide teaching situation.

Image situation to create. Iconicity of the creation of multimedia courseware situation, its essence is to solve the image thinking and abstract thinking, the relationship between perceptual knowledge and rational knowledge. Creating teaching situation, the most important is pay attention to students' real life, in students' daily life found in learning resources. Any effective teaching began in the students already had experience of making full use of. Effects of learning the single most important element is what the students already know, to verify this, and should according to teaching. Students experience including cognitive experience and life experience. Through the image of the creation of context, scene simulation example teaching, make the students seemed to be personally on the scene, in the exercise of real environment to display their talent, in positive thinking to improve the ability of solving practical problems. Therefore, multimedia courseware creating teaching situation, should be sensible and image, it can enrich students' perceptual knowledge, and promotes the perceptual knowledge to rational knowledge transformation and sublimation, it can effectively stimulate and inspire students' imagination and association, it can make the student beyond the narrow individual experience and the limit of time and space and make the students obtain knowledge at the same time. It can make students image thinking and abstract thinking development.

The establishment of question situation. Valuable teaching situation must be embedded question situation. It can effectively arouse students' thinking. Multimedia courseware creating 
problem situation to carry out the innovation teaching function main performance is: put forward the question by the teaching situation. Teaching information novelty, so that students curiosity and thirst for knowledge, to inspire students to explore the motivation and interest. It is helpful to cultivate students' innovation needs thinking quality and research ability. Hypothesized penetration and use some creative methods in the exploration and innovation process, to create a new theory, given the new method, in order to cultivate the students' innovative methods and scientific inquiry. The creation of multimedia courseware problem situations should be focusing on the teaching purposes, pay attention to cultivating students' divergent thinking and innovation consciousness.

\section{The Problems Should Pay Attention to Making Courseware}

When we create situations we must put the students on the status of the subject. Multimedia courseware should take advantage of situations to promote student active thinking, to provide students with self-exploration of time and space, as much as possible to let the students do, to enable students to "lively". Only through their own explore and experience, the students' innovative consciousness and innovative ability to continue to improve. Creation situations of multimedia courseware if we ignore the reaction of the students, lack of communication with students, it will reduce the enthusiasm of the students creation and courseware can not be a better guide the students to, the idea of thinking of the students can not be effectively extended.

When we create situations we must pay attention to orientation information application. Orientation information, as the name suggests is to guide the students to learn the direction information, it gives students explore the activities in the specified direction. It includes the guiding picture, oriented text and other information. guidance information setting affects directly the effect of situational creation. Oriented information should be specifically distinct, enlightening, inquiry. It is used to stimulate the students' thinking. Through the guidance information setting problems cause students to form the question consciousness and the sense of exploration. Set oriented information must conform to student's learning. Learning includes not only the students' knowledge of the original structure, study habits, learning method, learning ability, also includes students' learning attitude, growth environment, family background and learning potential, psychological quality etc. The creation of situational setting guide information, should concern about the students' existing cognitive structures, to research students' cognitive structure have no proper, can undertake the growth point of old knowledge.

\section{Summaries}

In short, the multimedia courseware as a supplementary teaching tool for modern education is a major bright spot; it will become the common demand of teachers and students. The class situation can not only enrich the teaching process, and improving teaching efficiency. With the aid of multimedia information technology can subtly into the students' emotional experience and appreciation experience closely, get along swimmingly with each other. We should conscientiously sum up the class teaching in the classroom experience, try to avoid and solve the problems in teaching process. In the actual teaching design, according to the different learning contents and student characteristics are more diverse creation, combines the traditional teaching and multimedia teaching courseware, focusing on pertinence and practicability of the courseware.

\section{References}

[1] Tiance Dong. Introduction to Communication Studies Chengdu: Sichuan University Press, 1995. Rong Xian. Design symbol [M] Beijing: Chemical Industry Press, 2004.

[2] Ouer Zhu. Courseware creation of situational to optimize language teaching process [J]. Zhejiang modern educational technology, 2002.04. 
[3] Xinhua Zhang. situations in the classroom of multimedia network environment creation [J]. The EDUCATIONAL study, 2001.05.

[4] Ke Lian. creation of situations of Multimedia Courseware [J]. Nanyang Institute of Technology, 2007.13. 